\title{
PREDICTIVE VALUES OF QUANTITATIVE ANALYSIS OF FINGER AND PALMAR DERMATOGLYPHICS IN PATIENTS WITH BREAST CANCER FOR BOSNIAN-HERZEGOVINIAN POPULATION
}

\author{
Jasmin Musanovic ${ }^{1}$, Azra Metovic ${ }^{2}$, Esad Pepic ${ }^{3}$, Dina Kapic ${ }^{4}$, Esad Cosovic ${ }^{5}$, Damir Rebic 6 , Orhan Lepara ${ }^{7}$ \\ 1 Medical Faculty, Department of Biology and Human Genetics, University of Sarajevo, Sarajevo, Bosnia and Herzegovina. \\ 2Medical Faculty, Department of Biology and Human Genetics, University of Sarajevo, Sarajevo, Bosnia and Herzegovina. \\ ${ }_{3}^{3}$ Medical Faculty, Department of Pathophysiology, University of Sarajevo, Sarajevo, Bosnia and Herzegovina. \\ ${ }_{4}^{4}$ Medical Faculty, Department of Histology and Embryology, University of Sarajevo, Sarajevo, Bosnia and Herzegovina. \\ 5 Medical Faculty, Department of Histology and Embryology, University of Sarajevo, Sarajevo, Bosnia and Herzegovina. \\ ${ }^{6}$ Medical Faculty, Department of Nephrology, Clinical Centre, University of Sarajevo, Sarajevo, Bosnia and Herzegovina. \\ ${ }^{7}$ Medical Faculty, Department of Physiology, University of Sarajevo, Sarajevo, Bosnia and Herzegovina.
}

\section{BACKGROUND}

ABSTRACT

Breast cancer is one of the most common cancers in women in Bosnia and Herzegovina, and this is a serious public health problem. Since the use of dermatoglyphics has a long history of application in different scientific fields, the objective of this research was to find possible relation between the finger and palmar dermatoglyphic patterns and breast cancer risk in females with no breast cancer within the Bosnian-Herzegovinian population.

\section{MATERIALS AND METHODS}

The study included a case group of 100 female patients with pathohistologically confirmed breast cancer and 132 healthy volunteer women as a control group with no familiar history of any type of cancers. Sampling was performed across Bosnia and Herzegovina using the Printake method. Qualitative and quantitative analysis of fingers and palms of both hands was performed.

\section{RESULTS}

A pattern of less than six finger loops was found more frequently in breast cancer patients than in the control group. The ATD angle and the b-c ridge count were increased in breast cancer patients in comparison with healthy subjects.

\section{CONCLUSION}

Dermatoglyphic analysis in combination with the assessment of other risk factors may be used as a cheap and non-invasive method in the prediction of breast cancer development.

\section{KEY WORDS}

Breast Cancer, Dermatoglyphics, Loops, ATD Angle, Prediction.

HOW TO CITE THIS ARTICLE: Musanovic J, Metovic A, Pepic E, et al. Predictive values of quantitative analysis of finger and palmar dermatoglyphics in patients with breast cancer for Bosnian-Herzegovinian population. J. Evolution Med. Dent. Sci. 2018;7(24): 2855-2860, DOI: $10.14260 /$ jemds/2018/644

\section{BACKGROUND}

Bosnia and Herzegovina is a small multiethnic country situated in the south-eastern Europe. The capital is city of Sarajevo. According to the World Health Organisation, every $12^{\text {th }}$ women is affected by breast cancer and is 100 times more in women than in men in the world. Similar situation is in Bosnia and Herzegovina.(1) This is one of the most common increasing hereditary based disease in female and today is being one of the most examined disease.(2) Risk of getting breast cancer is increased in women under stress, radiation exposure, family history, early menstruation and other risk factors.(3) Scientists were trying to find an effective and reliable non-invasive marker that can predict the illness in order to extend life.(4)

'Financial or Other Competing Interest': Dr. Mušanović reports grants from Federal Ministry of Education and Science of Federation of Bosnia and Herzegovina, outside the submitted work.

Submission 03-05-2018, Peer Review 26-05-2018,

Acceptance 02-06-2018, Published 11-06-2018.

Corresponding Author:

Dr. Jasmin Musanovic,

Assistant Professor,

Cekalusa 90, 71000

Sarajevo, Bosnia and Herzegovina.

E-mail: jasmin.m.gen@gmail.com

DOI: $10.14260 /$ jemds $/ 2018 / 644$ different fields of science and medicine, and they can be in some cases good non-invasive predictive tools for calculation of risks for many diseases and also for the breast cancer as well, concerning that they are constant, personally unique and they remain constant throughout life and have genetics base. Finger prints are very unique and even two identical twins have no same fingerprints. Together with finger patterns, estimative tools are the palmar prints from which it is possible to get more information than from the patterns from fingers.(5-7) By extracting information in available literature, there is no information of possible connection between breast cancer and dermatoglyphics as predictive tools for the breast cancer for Bosnian-Herzegovinian population. This is the first one. Also, it is important to stress that there is no complete statistical evidence about the number of breast cancer patients in Bosnia and Herzegovina and this study is done as a pilot study in order to demonstrate a possible relationship between breast cancer patients, healthy women predisposed to carcinoma breast and fingerprint and palmar dermatoglyphics in Bosnian and Herzegovinian population.

\section{Objectives}

1. To find out the useful quantitative parameters of fingers and palmar dermatoglyphics of both hands in case and 
control groups in order to predict the occurrence of breast carcinoma in healthy women.

2. To find out the useful qualitative parameters of fingers and palmar dermatoglyphics of both hands in case and control groups in order to predict the occurrence of breast carcinoma in healthy females.

\section{MATERIALS AND METHODS}

\section{Sampling}

This case control study included 100 female subjects in the case group and 132 females in the control group. The convenience sampling size was determined according to the similar studies in the world, because Bosnia and Herzegovina does not have statistic evidence about the total number of women with breast cancer. That is why our sample is made up by convenience and present as a pilot study for BosnianHerzegovinian population. All examinees were provided with appropriate information about aims, methods and purpose of this research. Ethical anonymity was provided by filling in the questionnaire form.

\section{Case Group}

In case (patients) group there were 100 women in the age group of 20 - 85 with pathohistologically confirmed breast cancer. Selection of these women included in the case group was made randomly of volunteers by following inclusion and exclusion criteria. All examinees had no history of any other genetically based disease or disorders.

Patients in the terminal phase of the disease were not included in the sampling. Sampling was performed throughout breast cancer associations in Bosnia and Herzegovina.

\section{Control Group}

In the control group were 132 healthy women, randomly selected volunteers, age ranged from 20 - 85, selected by the Department of Biology and Human Genetics, Medical School, University of Sarajevo with no familiar history of any type of cancers nor any other genetically based disorder or disease. For this group, inclusion and exclusion criteria were followed. Since we have worked with volunteers who wanted to test themselves for possible risk, we did not reject anyone who wanted to participate in the study.

\section{Inclusion Criteria}

- Female respondents.

- $\quad$ Age over 18 years of life.

- Informed consent- signed.

- $\quad$ Signed a questionnaire form.

- Pathohistologically confirmed diagnosis of breast cancer.

- Citizenship of Bosnia and Herzegovina.

- Absence of familiar histories associated to cancer.

\section{Exclusion Criteria}

- Medically confirmed diagnosis of other type of cancers.

- The presence of disability linked to the fingers of both hands.

- The presence of disability linked to the palm of both hands.

- The presence of genetically based diseases or disorders.
Fingers and palmar painting was performed by using Printake inked polyester foils by following methods previously described by Cummins and Midlo.(8)

\section{Dermatoglyphics}

Qualitative Analyses of Fingers

Arch- Area without drawings and in the literature is marked with letter A.

Tented Loop- Formation with triradius in the centre of the drawing, which is classified as half of ulnar and half of radial loop (topologically) and in the literature is denoted by T.

The Ulnar Loop- Pattern runs in the direction of radius. The central part and triradius are on the radial side; topologically is classified as the presence of radial component (value 2) and absence of ulnar (value 0 ) and traditionally is labelled by $U$.

The Radial Loop- Pattern runs in the direction of ulna and the triradius and the central part are located ulnarly. Topologically is classified as the presence of an ulnar component (value 2) and the absence of radial (value 0) and is traditionally labelled by $R$.

Whorl- Is a concentric or spiral drawing followed by two triradii; topologically as the presence of ulnar and radial loops. This category of drawings also belong to the double loops, as they are always accompanied by two triradii. Traditionally, the whorl is marked by letter $\mathrm{W}$.

\section{Quantitative Analyses of Fingers}

TFRC- The total ridge count that makes the sum of the ridges on all ten fingers, but for whorl only the higher ridge count is accepted or the absolute ridge count (ARC) when for whorl sums both values. In this research, only TFRC is calculated. FRCR1- Number of ridges on the first finger- right hand. FRCR2- Number of ridges on the second finger- right hand. FRCR3- Number of ridges on the third finger- right hand. FCR4- Number of ridges on the fourth finger- right hand. FRCR5- Number of ridges on the fifth finger- right hand. FRCL1- Number of ridges on the first finger- left hand. FRCL2- Number of ridges on the second finger- left hand. FRCL3- Number of ridges on the third finger- left hand. FRCL4- Number of ridges on the fourth finger- left hand. FRCL5- Number of ridges on the fifth finger- left hand.

\section{Qualitative Analyses of Dermatoglyphics on the Palms} The position of the axial triradius $t\left(t-\right.$ the angle is $45^{\circ}, t^{\prime}-$ the angle is $46-55^{\circ}$ and $t "-$ the angle is greater than $56^{\circ}$ is also analysed).

\section{Quantitative Analyses of Dermatoglyphic on the Palms}

- $\quad a-b$ rc R - number of ridges between the triradii a and triradius $b$ of the right hand.

- $\quad \mathrm{a}-\mathrm{b}$ rc L - number of ridges between triradii a and triradius $b$ of the left-hand.

- $\quad \mathrm{b}-\mathrm{c}$ rc R - number of ridges between triradii $\mathrm{b}$ and triradius $\mathrm{c}$ of the right hand.

- $\quad$ b-c rc L - number of ridges between triradii b and triradius $\mathrm{c}$ of the left hand. 
- $\quad \mathrm{c}-\mathrm{d}$ rc R - number of ridges between the triradius c and the triradius $\mathrm{d}$ of the right hand.

- $\quad$ c-d rc L - number of ridges between triradii c and triradius $d$ of the left hand.

- $\quad$ ATD-R - the angle size between triradii a, $t$ and $d$ of the right hand measured in degrees.

- $\quad$ ATD-L - the angle size between triradii a, $t$ and $d$ of the left hand measured in degrees.

Counting was done by a magnifier that had an embedded LED lamp with three diopters.

\section{Statistical Analyses}

Statistical analysis was performed using IBM SPSS Statistics version 21.0. Data are presented as mean \pm SD and as median and interquartile ranges. Data distribution was determined using the Kolmogorov-Smirnov test. Data were statistically analysed with the non-parametric Mann-Whitney U test and parametric student's t-test. In the analysis of the dependence between categorical variables, chi-square test and Fisher's exact test were performed. A p-value of $<0.05$ was considered statistically significant.

\section{RESULTS}

\section{Qualitative Analysis of Fingers}

For the Arches- statistically significant difference was not observed between the examined and the control group, $\mathrm{p}=0.325$.

For the Loops- statistically significant difference was observed in the number of loops on the fingers of both hands of 6 or more loops between the control group $p=0.014$ in comparison to women with breast cancer as well as the statistically significant difference in the number of loops on the fingers of both hands of 6 and less than six in women with breast cancer compared to the control group $p=0.014$.

For the Whorls- there was no statistically significant difference in the number of whorls for all fingers of both hands for pattern of 6 or more than 6 whorls as well as over 6 between the examined and control group $p=0.070$ (Table 1 ).

\section{Quantitative Analysis of Fingers}

TFRC- By comparing the value of the total number of papillary ridges on all ten fingers, there were no statistically significant differences between the two groups, $p=0.569$. The total number of papillary ridges on all ten fingers in the examined group was (114), while in the control group the total number of ridges was slightly lower (110) (Table 2).

\section{FRC}

No significant differences were observed between the breast cancer patients and the control groups in FRC counts. The values of the number of papillary ridges were similar in both the right and left fingers (Table 2).

\section{Qualitative and Quantitative Analysis of Palmar Dermatoglyphics- \\ ABRCR}

The difference in the number of epidermal ridges between triradius $\mathrm{A}$ and triradius $\mathrm{B}$ of the right hand did not have statistical significance $(p=0.277 ; p>0.05)$. Similar situation was for the ABRCL, where $p=0.075 ; p>0.05$.

\section{BCRCR}

The number of ridges between triradius $B$ and triradius $C$ of the right hand in the examined group was $29.64 \pm 6.19$, while in the control group was $27.59 \pm 7.46$. It was observed that patients had a greater number of epidermal ridges between triradius $\mathrm{B}$ and triradius $\mathrm{C}$ of right hand and it was statistically significant difference $(p=0.026, p<0.05)$.

\section{BCRCL}

The number of ridge between triradius $B$ and triradius $C$ of the left hand in the examined group was $28.97 \pm 6.32$, while in the control group was $27.04 \pm 6.57$. The difference between the number of ridges between triradius $B$ and triradius $C$ was statistically significant $(p=0.026 ; p<0.05)$, patients group had a greater number of epidermal ridges between these two triradii on the left hand.

\section{CDRCR}

The difference in the number of ridges between triradius $\mathrm{C}$ and triradius $\mathrm{D}$ of the right hand did not show statistical significance $(p=0.797, p>0.05)$. Similar results were for the CDRCL, where $\mathrm{p}=0.263, \mathrm{p}>0.05$ (Table 3.)

\section{ATD Angle}

There was a statistically significant difference between the median values of the ATD angle of palms of both hands, $\mathrm{p}<0.001$ (Table 3). Also by comparing the frequency of axial triradii between the group of breast cancer patients and the phenotypically healthy population, a statistically significant difference was established. It was observed that ATD angle was higher in the breast cancer patients $(\mathrm{p}=0.001, \mathrm{p}<0.05)$. Also, it was observed that ATD angle of left hand was also higher in patients with breast cancer and the results were statistically significant $(\mathrm{p}=0.001, \mathrm{p}<0.05)$ (Table 4).

Other factors considered to be epidemiological factors contributing to the development of breast cancer were also studied. Statistical significance was observed in three factors: breastfeeding, contraception and mammography (Table 5).

\begin{tabular}{|c|c|c|c|c|}
\hline \multicolumn{2}{|c|}{ Variable } & $\begin{array}{c}\text { Control Group } \\
(\mathbf{n = 1 3 2})\end{array}$ & $\begin{array}{c}\text { Patients/Cases } \\
(\mathbf{n = 1 0 0 )}\end{array}$ & P value \\
\hline \multirow{2}{*}{$\begin{array}{c}\text { ARCH } \\
\text { (have/present) }\end{array}$} & $33(25.2 \%)$ & $29(28.7 \%)$ & \multirow{2}{*}{0.325} \\
\hline \multirow{2}{*}{ Whorl } & $<6$ & $113(85.6 \%)$ & $78(77.2 \%)$ & \multirow{2}{*}{0.070} \\
\cline { 2 - 5 } & $>6$ & $19(14.4 \%)$ & $23(22.8 \%)$ & \\
\hline \multirow{2}{*}{$\begin{array}{c}\text { Loops } \\
\text { (Total) }\end{array}$} & $<6$ & $31(23.5 \%)$ & $38(37.6 \%)$ & \multirow{2}{*}{0.014} \\
\cline { 2 - 4 } & $>6$ & $101(76.5 \%)$ & $63(62.4 \%)$ & \\
\hline \multicolumn{4}{|c|}{ Table 1. Qualitative Fingerprint Parameters } \\
\hline
\end{tabular}

\begin{tabular}{|c|c|c|c|}
\hline Variable & $\begin{array}{c}\text { Control Group } \\
(\mathbf{n = 1 3 2})\end{array}$ & $\begin{array}{c}\text { Patients/ } \\
\text { Cases } \\
(\mathbf{n = 1 0 0 )}\end{array}$ & P value \\
\hline FRCR1 & $14(11-17)$ & $15(10-18)$ & 0.522 \\
\hline FRCR2 & $11(255-14)$ & $12(5-16)$ & 0.197 \\
\hline FRCR3 & $10(8-13)$ & $10(7-14)$ & 0.688 \\
\hline FRCR4 & $12(10-15)$ & $13(10-16)$ & 0.450 \\
\hline FRCR5 & $11(8-13)$ & $11(8-14)$ & 0.511 \\
\hline FRCL1 & $13.01 \pm 5.76$ & $13.04 \pm 6.85$ & 0.976 \\
\hline FRCL2 & $10(5-14)$ & $11(6-13)$ & 0.936 \\
\hline FRCL3 & $10(7-13)$ & $11(5.75-12)$ & 0.467 \\
\hline FRCL4 & $12.5(9-16)$ & $12(8-15)$ & 0.964 \\
\hline FRCL5 & $10.59 \pm 4.82$ & $11.39 \pm 5,35$ & 0.235 \\
\hline TFRC & $110(84-142)$ & $114(81-152)$ & 0.569 \\
\hline \multicolumn{4}{|c|}{ Table 2. Quantitative Fingerprint Parameters } \\
\hline
\end{tabular}




\begin{tabular}{|c|c|c|c|}
\hline Variable & $\begin{array}{c}\text { Control } \\
\text { Group } \\
(\mathbf{n = 1 3 2})\end{array}$ & $\begin{array}{c}\text { Patients/Cases } \\
\text { (n= 100) }\end{array}$ & P value \\
\hline ABRCR & $44(40-48)$ & $43(38-47)$ & 0.277 \\
\hline ABRCL & $43(40-47)$ & $41(37-46)$ & 0.075 \\
\hline BCRCR & $27.59 \pm 7.46$ & $29.64 \pm 6.19$ & 0.026 \\
\hline BCRCL & $27.04 \pm 6.57$ & $28.97 \pm 6.32$ & 0.026 \\
\hline CDRCR & $39(33-43)$ & $38(34-42)$ & 0.797 \\
\hline CDRCL & $41(34-45.75)$ & $39(35-43.75)$ & 0.263 \\
\hline ATDR & $47(43.25-50)$ & $49.5(46-52)$ & $<0.001$ \\
\hline ATDL & $47(44-50)$ & $49(47-52)$ & $<0.001$ \\
\hline \multicolumn{4}{|c|}{ Table 3. Quantitative Parameters of Palmar } \\
Dermatoglyphics \\
\hline \multicolumn{4}{|c}{}
\end{tabular}

\begin{tabular}{|c|c|c|c|c|}
\hline \multicolumn{2}{|c|}{ Variable } & $\begin{array}{c}\text { Control Group } \\
(\mathbf{n = 1 3 2})\end{array}$ & $\begin{array}{c}\text { Patients/Cases } \\
(\mathbf{n = 1 0 0 )}\end{array}$ & P value \\
\hline \multirow{3}{*}{ ATDR } & $\leq 45^{\circ}$ & $52(39.4 \%)$ & $17(17.0 \%)$ & \multirow{2}{*}{$<0.001$} \\
\cline { 2 - 4 } & $>46^{\circ}$ & $80(60.6 \%)$ & $83(83.0 \%)$ & \\
\hline \multirow{4}{*}{ ATDL } & $\leq 45^{\circ}$ & $50(37.9 \%)$ & $18(18.0 \%)$ & \multirow{2}{*}{$<0.001$} \\
\cline { 2 - 4 } & $>46^{\circ}$ & $82(62.1 \%)$ & $82(82.0 \%)$ & \multirow{2}{*}{ Table 4. ATD Angle- Qualitative Results } \\
\cline { 2 - 4 } & $>6$ & $101(76.5 \%)$ & $63(62.4 \%)$ & \\
\hline \multicolumn{4}{|c|}{ Tablive } \\
\hline
\end{tabular}

\begin{tabular}{|c|c|c|c|}
\hline Variable & $\begin{array}{c}\text { Control Group } \\
(\mathbf{n = 1 3 2})\end{array}$ & $\begin{array}{c}\text { Patients/Cases } \\
\text { (n= 100) }\end{array}$ & P value \\
\hline Age (Years) & $51.29 \pm 5.67$ & $53,04 \pm 4.89$ & 0.137 \\
\hline Contraception & $14(10.9 \%)$ & $31(32.3 \%)$ & $<0.001$ \\
\hline $\begin{array}{c}\text { Malignancy in } \\
\text { the family }\end{array}$ & $63(48.8 \%)$ & $51(53.4 \%)$ & 0.308 \\
\hline Breastfeeding & $86(67.2 \%)$ & $77(80.2)$ & 0,021 \\
\hline $\begin{array}{c}\text { Duration of } \\
\text { breastfeeding } \\
\text { (Months) }\end{array}$ & $4(0-12)$ & $6(1-12)$ & 0.211 \\
\hline Smoking & $50(38.5 \%)$ & $41(42.7 \%)$ & 0.306 \\
\hline Alcohol & $6(4.7 \%)$ & $8(8.4 \%)$ & 0.195 \\
\hline Menarha (Year) & $14(13-14)$ & $14(13-15)$ & 0.231 \\
\hline $\begin{array}{c}\text { Exposure to } \\
\text { radiation }\end{array}$ & $2(1.5 \%)$ & $6(6.3 \%)$ & 0.063 \\
\hline $\begin{array}{c}\text { Spontaneous } \\
\text { abortions }\end{array}$ & $21(16.4 \%)$ & $24(25.3 \%)$ & 0.073 \\
\hline Mammography & $41(31.8 \%)$ & $71(74.0 \%)$ & $<0.001$ \\
\hline \multicolumn{4}{|c|}{ Table 5. Other Risk Parameters } \\
\hline
\end{tabular}

\section{DISCUSSION}

Dermatoglyphics in many number of diseases, mostly genetically based (different trisomy) can be used like noninvasive, anthropomorphical, anatomical markers as a predictor for certain disease.(9)

In this study, a statistically significant difference was observed in a 6 or more looped control group compared to women with breast cancer, which is contrary to the results of Seidman et al 1982,(10) as they described more loops at persons with breast cancer compared to control, which is not the case for the Bosnian-Herzegovinian population. In other studies,(11) it was claimed that women with more than 6 loops on their fingerprint samples had 46 times higher risk of developing breast cancer compared to controls. In this discovery of the division of the loops on the ulnar or radial, there was no statistically significant difference between the control and the examined group and as such there is no estimative value in the risk assessment. In some studies, it has been shown that such division plays a significant role in the estimation of the risk, since it has been found that the ulnar loop is significantly associated with breast cancer.(12)
In most cases, a sample of 6 and more than six whorls in breast cancer patients is described as a very protective risk assessment indicator for breast cancer, but in our case there was no statistical significance $(p=0.070) .(11)$ When it comes to the number of arches, no statistical significance has been observed between the examined and the control group, which does not coincide with the results of other authors(13) who recorded the increase in the number of arches on the fingers of both hands in affected women.

Quantitative analysis of digital dermatoglyphics involves the analysis of the number of papillary ridges between the triradius and the center of the drawing at the top of each finger of the right or left hand. Since dermatogenes consider the indicators of events in early embryonic life, their analysis can be used in the aetiology of some diseases suspected of having a hereditary basis. Forms of dermal ridges are considered to be biomarkers of our genes, reflecting the DNA pattern and genetic instability. Different variables of dermal ridges in different breeding areas reflect the state of the specific gene.(14) Genomics participating in the development of fingers and palmar dermatoglyphics differ in patients with cancer from the general population. This is possible because these genes play a significant role in the predisposition to develop malignancy.(6)

In some of the studies, the results of the analysis of quantitative parameters of dermatoglyphics have shown statistically significant differences between persons suffering from malignant disease in relation to the control group or breast cancer patients with a lower total number of digital ridges.(15) Some authors believe that this method could be used in the future as "screening" in determining the risk of breast cancer.

No significant differences were observed between the breast cancer patients and the control group in the number of ridges for FRC. Even at one of the ten fingers, the number of ridges in the subjects compared to the control group was not significantly different and this was not the case with other similar studies, because there was a significant difference between the control and the examined female group in their research.(15,16)

By comparing the value of the total number of papillary ridges on all ten fingers, there was no statistically significant difference between the two examined groups and which is not related to similar researches. An increase in the total number of papillary ridges was recorded in a large number of studies.(17,18) Raizde et al 2013 in their results show that total values less than 50 ridges of total fingerprints associated with breast cancer, while higher values of total ridges (above 100) are more common in healthy subjects indicating that lower values of total number of ridges can be associated with the risk of developing breast cancer, but no statistical significance for the values of this parameter has been recorded in our research and such has no estimative value.

Statistical significance for ABRCR and ABRCL was not found in this study, which is not the case with similar earlier studies in which it has been found an increased number of ridges on both hands. ${ }^{(2,19)}$ But it should be noted that for the Bosnian-Herzegovinian population, it is found a statistically significant difference for BCRCR with a greater number of epidermal ridges between triradius $B$ and triradius $C$ of the right hand and for BCRCL a greater number of epidermal ridges between triradius $B$ and $C$ triradius $C$ of the left hand. 
These values could be useful together with other significant predictive markers. Significant results are recorded in a similar research. ${ }^{(20)}$

There was no statistically significant difference between CDRCR and CDRCL and it cannot be useful for breast cancer prediction for the Bosnian-Herzegovinian population, despite the studies reported statistically significant decrease in the number of ridges on the left hand.(20)

Differences in the quantitative properties of dermatoglyphic palmar complex between the examined group (Women with breast cancer) and the control group (Phenotypic healthy women) were found in this study. ATD angle analysis showed a statistically significant difference between the examined and the control group.

The results of our research indicate that axial triradius are higher in the examined group compared to the control group, which is in line with the results of the similar investigations.(11,21) But it is important to stress that in some other researches this was not the situation, because they found lower axial triradius in the patient's group. $(15,22)$

Based on this study it was found that breastfeeding have no protective role in breast cancer, because the breast cancer patients have a significant proportion of breast-feeding compared to the control group. The hypothesis that breastfeeding reduces the risk of breast cancer is the subject of many discussions. The results of studies of different populations studying lactation and risk of breast cancer are inconsistent and variable.(23)

This study showed that there was a significant difference between the examined and the control group in terms of the use of contraceptives, that is much higher number of female patients (32.2\%) used some form of contraception than in a control group (10.9\%). Here is a similar situation like it was with the breastfeeding. It can be said that the oral contraceptives can be a risk factor for the development of breast cancer and there is support for something like this in literature.(24) In this study the results show that more subjects were exposed to the x-ray examination method, mammography. Even $74.0 \%$ of respondents were exposed to a certain radiation dose indicating that mammography could be a risk factor for breast cancer, as statistically significant results $(\mathrm{p}=0.001, \mathrm{p}<0.05)$ were obtained. Some authors in their papers indicate that the women with benign form of breast cancer have a high risk of developing breast cancer if they are exposed to a certain dose of radiation. $(25,26)$

\section{CONCLUSION}

The quantitative and qualitative values of dermatoglyphics themselves cannot be an absolute non-invasive usable marker for assessing the risk of breast cancer, but the most effective results are in terms of the usability of the ATD angle score and the number of loops and together with other risk factors such as breastfeeding, contraception and mammography, can be a useful tool for assessing the risk of breast cancer for the Bosnian-Herzegovinian population.

For Bosnian-Herzegovinian women in the control group, where it was shown to have increased risk for breast cancer, it is important to do genetic analysis of BRCA 1 and BRCA 2 genes, because these genes have been associated with increased risk for breast cancer in women.

\section{ACKNOWLEDGEMENTS}

The authors are grateful to the Federal Ministry of Education and Science of Federation of Bosnia and Herzegovina, which supported this research (No. 05-39-3958/-1/15) by grant associations of women with breast cancer from Bosnia and Herzegovina, healthy women for participating in the control group.

\section{REFERENCES}

[1] Gledo I, Pranjic N, Parsko S. Quality of life factor as breast cancer risks. Materia Socio-Medica 2012;24(3):171-7.

[2] Krishnan S, Natesan D. Dermatoglyphics in carcinoma breast. J Evolution Med Dent Sci 2016;5(89):6630-3. DOI: $10.14260 /$ jemds/2016/1500.

[3] Gledo I, Pranjic N, Drljević K, et al. Female breast cancer in relation to exposure to medical iatrogenic diagnostic radiation during life. Contemporary Oncology (Pozn) 2012;16(6):551-6.

[4] Seltzer MH, Plato CC, Engler PE, et al. Digital dermatoglyphics and breast cancer. Breast Cancer Res Tret 1982;2(3):261-5.

[5] Sridevi NS, Silva CRWD, Kulkarni R, et al. Palmar dermatoglyphics in carcinoma breast of Indian women. Rom J Morphol Embryol 2010;51(3):547-50.

[6] Sofia P, Velichety SD, Chandrasekharan PA, et al. Qualitative and quantitative analysis of digital dermatoglyphics in female reproductive cancers. Int J Anat Res 2016;4(3):2603-8.

[7] Raizada A, Johri V, Ramnath T, et al. A cross-sectional study on the palmar dermatoglyphics in relation to carcinoma breast patients. J Clin Diagn Res 2013;7(4):609-12.

[8] Cummins H, Midlo C. Finger prints, palms and soles: an introduction to dermatogliphycs. New York: Dover Publication Inc., 1943.

[9] Shazya G, Nusrat J, Sangeeta G, et al. Palmar dermatoglyphic and breast cancer: a possible correlation. International Journal of Medical and Health Research 2018;4(2):53-5.

[10] Seidman H, Stellman SD, Mushinski MH. A different perspective on breast cancer risk factors: some implications of the nonattributable risk. CA Cancer J Clin 1982;32(5):301-13.

[11] Natekar PE, DeSouza FM, Motghare DD, et al. Digital dermal patterns in carcinoma breast. The Anthropologist 2006;8(4):251-4. DOI: 10.1080/09720073.2006.11890972

[12] Gamel JW. Digital dermatoglyphics in mammary cancer. Cancer Invest 1989;7(3):301-2.

[13] Ajeena EH. Study the advantage of dermatoglyphics in detecting women with breast cancer. Al-Kufa University Journal for Biology 2015;7(3):1-6.

[14] Prathap L, Jagadeesan V, Suganthirababu P, et al. Association of quantitative and qualitative dermatoglyphic variable and DNA polymorphism in female breast cancer population. Online J of Health and Allied Scis 2017;16(2):2. 
[15] Lavanya J, Saraswathi P, Vijayakumar J, et al. Analysis of dermatoglyphic traits in patients with breast cancer. Journal of Pharmaceutical and Biomedical Sciences 2012;23(23):1-5.

[16] Chintamani, Khandelwal R, Mittal A, et al. Qualitative and quantitative dermatoglyphic traits in patients with breast cancer: a prospective clinical study. BMC Cancer 2007; 7:44.

[17] Inamdar VV, Vaidya SA, Kulkarni $P$, et al. Dermatoglyphics in carcinoma of cervix. Journal of Anatomical Society of India 2006;55(1):57-9.

[18] Buković D, Persec Z, Buković N, et al. Qualitative dermatoglyphic traits in ovarian cancer patients: a case-control study. Coll Antropol 1999;23(2):641-4.

[19] Mardanshahi O, Khayatzadeh J, Shahidsales S. The relation between the anthropometric characteristics of fingers and cancer. Reviews in Clinical Medicine 2017;4(3):124-7. doi: 10.22038/rcm.2017.9265.

[20] Birsen Ö, Ahmet S, Mustafa S, et al. Dermatoglyphics as markers of prenatal disturbances in schizophrenia: a case-control study. Turk J Med Sci 2010;40(6):917-24.

[21] Oladipo GS, Paul CW, Bob-Manuel IF, et al. Study of digital and palmar dermatoglyphic patterns of Nigerian women with malignant mammary neoplasm. Journal of Applied Biosciences 2009;15:829-34.
[22] Madhavi D, Dorairaj S, Dorairaj SSJ, et al. Dermatoglyphic study in breast carcinoma patients. International Journal of Science and Research 2016;5(10):837-40.

[23] Freund C, Mirabel L, Annane K, et al. Breastfeeding and breast cancer. Gynecol Obstet Fertil 2005;33(10):73944.

[24] Soroush A, Farshchian N, Komasi S, et al. The role of oral contraceptive pills on increased risk of breast cancer in Iranian populations: a meta-analysis. J Cancer Prev 2016;21(4):294-301.

[25] Friedenson B. Is mammography indicated for women with defective BRCA genes? Implications of recent scientific advances for the diagnosis, treatment and prevention of hereditary breast cancer. Med Gen Med 2000;2(1):E9.

[26] Preston DL, Mattsson A, Holmberg E, et al. Radiation effects on breast cancer risk: a pooled analysis of eight cohorts. Radiat Res 2002;158(2):220-35. 